\title{
Epidemiological survey of rheumatic heart disease among school children in the Shimla Hills of northern India: prevalence and risk factors
}

\author{
Jarnail S Thakur, Prakash C Negi, Surendra K Ahluwalia, Nand K Vaidya
}

\begin{abstract}
Study objective - To determine the prevalence of rheumatic heart disease (RHD) and study the relationship of this disease to factors such as age, sex, housing, and socioeconomic status in Shimla town and the adjoining rural area.

Design - A cross sectional survey, carried out by a specially trained examiner in cardiology.

Setting - The study involved high risk school children (5-16 years of age) from Shimla town and the adjoining rural area of Kasumpti-Suni Block in the period 1992-93.
\end{abstract}

Subjects - A total of 15080 children on the school register (8120 boys and 6960 girls) were examined generally and specifically for evidence of RHD.

Main results - Of the 15080 children screened, the prevalence of rheumatic fever (RF)/RHD was 2.98 per thousand with no significant difference between the age groups of 5-10 and 11-16 years or in either sex $(p>0.05)$. The prevalence was significantly greater in rural schools $(4 \cdot 8 /$ 1000) than in urban schools $(1 \cdot 98 / 1000)$ $(p<0 \cdot 05)$. There was overcrowding and poor housing in most cases. There were fewer cases of RHD with severe valvular lesions in the younger age group than in the older children. The mitral valve was the valve most commonly affected by RF/ RHD.

Conclusions - RHD continues to be a serious health problem. Regular surveys are needed to identify cases early and to ensure secondary prophylaxis with penicillin is given thereby preventing recurrence of $R F$ and progression of the severity of the valvular lesion. Echocardiography is necessary to identify cases of RF/RHD. Strategies for preventing RHD should involve primary prevention to avert the first attack of carditis and strengthening of secondary prophylaxis through improved education and motivation of patients, parents, and physicians.

\section{( $f$ Epidemiol Community Health 1996;50:62-67)}

Rheumatic heart disease (RHD) is a problem that affects each corner of the globe, especially the developing countries. In India, $32-50 \%$ of all cardiac cases result from rheumatic fever
(RF)/RHD and this constitutes a major health problem. ${ }^{1}$ The extent and nature of the problem has been well documented by both hospital and community based studies. This malady affects adversely a large proportion of the population It has been estimated that about two million children are affected by this disease in India. A multicentre study on the epidemiology of RHD, under the aegis of Indian Council of Medical Research (ICMR) gave the national average of RHD prevalence as 6 per thousand in the age group of 5-16 years. ${ }^{2}$ The only preliminary study undertaken in the hilly area of Himachal Pradesh was in 1956. This showed a prevalence of 39 per thousand among the 1515 school children in Shimla, the highest prevalence ever reported in India. ${ }^{3}$ The obvious pitfall of this study was that investigating facilities were meagre then and there was considerable lack of awareness among the public about this illness. We therefore undertook a school based study to investigate the current extent of the problem.

\section{Methods}

GEOGRAPHIC AREA

Himachal Pradesh is a picturesque hilly state in northern India, with a population of 5170877 and a population density of $93 \mathrm{~km}^{2}$. The study was based on a survey carried out among school children in Shimla town and the adjoining area of Kasumpti-Suni Block, Shimla District, Himachal Pradesh.

\section{METHOD OF SAMPLING}

All the schools in Shimla town and KasumptiSuni Block were grouped into four categories rural government, urban government, convents, and private schools. There were 141 rural government, 99 urban government, 15 convent, and 9 private schools in the survey area, and of these $31,18,8$, and 5 respectively were selected randomly. A stratified random sample of 16082 children out of 40950 children in the age group of 5-16 years from these schools were selected for the study.

All the children present in a class at the time of the visit were examined in one sitting by a doctor (JST) who had trained for six months in cardiology especially for this purpose. History of past and present joint pains, fever, sore throat, palpitation, fatigue, shortness of breath, and chest pain were elicited and recorded on an initial screening proforma. Clinical examination 
Table 1 Age and sex distribution of children screened

\begin{tabular}{|c|c|c|c|c|c|c|c|c|}
\hline \multirow{2}{*}{$\begin{array}{l}\text { Age group } \\
\text { (y) }\end{array}$} & \multicolumn{2}{|c|}{ Children screened } & \multicolumn{2}{|c|}{ Children recalled } & \multicolumn{2}{|c|}{$\begin{array}{l}\text { Suspected } \\
R F / R H D\end{array}$} & \multicolumn{2}{|c|}{$\begin{array}{l}\text { Definite } \\
R F / R H D\end{array}$} \\
\hline & $M$ & $F$ & $M$ & $F$ & $M$ & $F$ & & $F$ \\
\hline $\begin{array}{l}5-10 \\
11-16\end{array}$ & $\begin{array}{l}3567 \\
4553\end{array}$ & $\begin{array}{l}2987 \\
3973\end{array}$ & $\begin{array}{l}262 \\
292\end{array}$ & $\begin{array}{l}237 \\
302\end{array}$ & $\begin{array}{l}16 \\
28\end{array}$ & $\begin{array}{l}12 \\
45\end{array}$ & $\begin{array}{r}7 \\
16\end{array}$ & $\begin{array}{r}8 \\
14\end{array}$ \\
\hline
\end{tabular}

$\mathbf{M}=$ male; $\mathrm{F}=$ female; $\mathrm{RF}=$ rheumatic fever $\mathbf{R H D}=$ rheumatic heart disease

was performed to look for objective evidence of RF and RHD. Particular care was taken in auscultating the child in erect, left lateral, and recumbent positions. In doubtful cases, children were also auscultated after exercise. An attempt was made to include the absentees during subsequent visits or by home visits (maximum two visits).

Parents of the children aged below 10 years and all the children aged above 10 years were asked about the family income. A modified Prasad's classification based on family income was used to determine the socioeconomic status of the children. ${ }^{4}$

The following types of patients were then recalled to the Indira Gandhi Hospital to be examined by a cardiologist to rule out observer's bias:

- Suspected and definite cases of RHD;

- History of RF with or without carditis;

- History suggestive of RF with or without carditis;

- Past history of RF or previous history suggestive of RF;

- Suspected and definite cases of congenital heart diseases;

- Patient with an ejection systolic murmur with grade I-II/VI functional murmur with or without history of RF.

The following types of patients were subjected to detailed echocardiographic examination after evaluation by the cardiologist:

- Suspected and definite cases of RHD and congenital heart disease;

- History of RF with or without carditis;

- Past history of RF;

- Previous history suggestive of RF with functional murmur.

These cases were also subjected to following investigations: chest $x$ ray (PA view); 12 lead electrocardiogram, haemoglobin, total leucocyte count, differential leucocyte count, erythrocyte sedimentation rate, ASO titre, and $C$ reactive protein; and a throat swab for $\beta$-haemolytic streptococci (BHS). An Advanced Technology Laboratories (ATL) Ultramark 7 echocardiograph with facilities for 2D, M mode, and Doppler ultrasonography was used for the study. Jones revised criteria were used for the diagnosis of RF. ${ }^{5}$

A home visit was made to the diagnosed cases of RF/RHD to study the housing conditions in accordance with WHO expert committee criteria for healthful housing and also the personal observation of examiner.

For analysis, the following definitions were used:
- Acute RF: those patients who fulfilled revised Jones criteria at the time of screening, with no history of RF in the past.

- Probable RHD: thickening of mitral and/or tricuspid valve seen on echocardiography, with previous history of RF or thickening of aortic valve and without Doppler evidence of valvular dysfunction.

- Definite RHD: clinical and echocardiographic evidence of chronic RHD.

\section{Results}

AGE AND SEX DISTRIBUTION OF THE CHILDREN

The age and sex distribution of the children is shown in Table 1. A total of $15080(93.7 \%)$ school children were examined out of a sample of 16082 children selected for the study. Altogether $8120(53.8 \%)$ of the total children screened were boys whereas only $6960(46 \cdot 2 \%)$ were girls. $6554(43.5 \%)$ children were in the age group of 5-10 years and $8526(56 \cdot 6 \%)$ were in the age group of 11-16 years. There was almost equal distribution of male and female children in both age groups $(p>0 \cdot 05)$.

PREVALENCE OF RF AND RHD

Out of 15080 children screened, 1116 (7.4\%) with a history of RF and a heart murmur on clinical examination, or both, were called for detailed examination by a cardiologist. Twenty three $(2 \%)$ children were non-responders - nine were suspected RF/RHD and congenital heart disease (CHD), and five had a functional murmur.

\section{Suspected and definite cases of $R H D$}

After a second screening by a cardiologist, 101 cases were suspected of having RF/RHD (table 1) and 49 were suspected of having CHD. The rest of the children were found to have a functional murmur or a history of non-rheumatic joint pains and hence did not undergo further investigations. All the children suspected of having RF/RHD and CHD had echocardiography and other investigations. A past history of RF with or without carditis was present in 38 $(37 \cdot 6 \%)$. Fifty seven $(56 \cdot 4 \%)$ had a history suggestive of RF, with or without carditis, and in six (5.9\%) there was no past history of RF.

A clinically definite diagnosis of RHD was made in $26(25.7 \%)$ children, confirmed on echocardiography, and a probable diagnosis in $75(74 \cdot 25 \%)$ cases. Six (8\%) of the clinically probable group were found to be suffering from definite RHD and 12 (16\%) had echocardiographic evidence suggestive of RHD. Of the six with definite RHD, three (50\%) had Gr II/VI ejection systolic murmur at the mitral area and three $(50 \%)$ had no murmur but a past history of RF. In total, therefore, there were 32 $(31.68 \%)$ cases of definite RHD and 12 $(11.88 \%)$ of probable RHD on echocardiography, giving the overall prevalence rate of RHD as 2.92 per thousand.

There were three clinically definite cases of acute RF, two had carditis confirmed on echocardiography but the third had no carditis and 
Table 2 Prevalence of rheumatic heart disease (RHD) and the incidence of acute rheumatic fever $(R F)$ and rheumatic fever recurrence in different types of schools

\begin{tabular}{|c|c|c|c|c|c|}
\hline Type of school & $\begin{array}{l}\text { Definite } \\
\text { RHD }\end{array}$ & $\begin{array}{l}\text { Probable } \\
\text { RHD }\end{array}$ & $\begin{array}{l}\text { Overall } \\
\text { prevalence }\end{array}$ & Acute $R F$ & $\begin{array}{l}R F \\
\text { recurrence }\end{array}$ \\
\hline $\begin{array}{l}\text { Rural government }(\mathrm{n}=4989) \\
\text { Urban government }(\mathrm{n}=3884) \\
\text { Convent }(\mathrm{n}=4359) \\
\text { Private }(\mathrm{n}=1848) \\
\text { Total } \mathrm{n}=15080\end{array}$ & $\begin{aligned} & 19(3.8) \\
& 9(2 \cdot 32) \\
& 2(0.46) \\
& 2(1.08) \\
& 32(2 \cdot 12) \\
& \chi^{2}=13.40 \\
&(\mathrm{p}<0.01)\end{aligned}$ & $\begin{array}{l}5(1) \\
1(0 \cdot 26) \\
5(1 \cdot 15) \\
1(0.54) \\
12(0 \cdot 8) \\
\mathrm{NS}\end{array}$ & $\begin{array}{l}24(4 \cdot 8) \\
10(2 \cdot 57) \\
7(1 \cdot 6) \\
3(1 \cdot 62) \\
44(2 \cdot 92) \\
\chi^{2}=9 \cdot 94 ; \\
(p<0.05)\end{array}$ & $\begin{array}{l}1(0 \cdot 2) \\
1(0 \cdot 26) \\
0 \\
1(0 \cdot 54) \\
3(0 \cdot 19) \\
\mathrm{NS}\end{array}$ & $\begin{array}{l}3(0 \cdot 6) \\
1(0 \cdot 26) \\
0 \\
0 \\
4(0 \cdot 26) \\
\mathrm{NS}\end{array}$ \\
\hline
\end{tabular}

Figures given in parentheses are the prevalence/incidence rate per thousand

Table 3 Distribution of rheumatic fever/rheumatic heart disease (RF/RHD) cases according to socioeconomic status

\begin{tabular}{lccl}
\hline Social class & $\begin{array}{l}\text { Total children } \\
(\%)\end{array}$ & $\begin{array}{l}\text { No of } R F / R H D \\
\text { cases }\end{array}$ & $\begin{array}{l}\text { RF/RHD prevalence } \\
\text { per thousand }\end{array}$ \\
\hline I & $1756(11 \cdot 6)$ & 0 & 0 \\
II & $2812(18.6)$ & 7 & 2.49 \\
III & $4052(26.9)$ & 11 & $2 \cdot 71$ \\
IV & $4280(28.4)$ & 17 & 3.97 \\
V & $2180(14.5)$ & 10 & 4.59 \\
Total & $15080(100)$ & 45 & 2.98 \\
& & $\chi^{2}=8 \cdot 87 ;(p>0 \cdot 05)$ & \\
\hline
\end{tabular}

echocardiography was normal. This gave an incidence rate for acute $R F$ as 0.19 per thousand. There were four cases with $R F$ recurrence. This was confirmed by laboratory investigations and echocardiography, giving an incidence rate of 0.32 per thousand. Two patients with acute RF had developed RHD with valvular dysfunction at the time of study and hence were included among 44 RHD cases. In total there were 45 cases of RF/RHD out of 15080 school children, giving an overall prevalence of 2.98 per thousand. Thus, out of 1093 children selected for detailed examination/investigations, 45 had RF/ RHD, 34 had CHD, 912 had a functional murmur, and 102 had non-rheumatic joint pains. The prevalence of functional murmur was $6.04 \%$.

\section{Initial screening and subsequent visit to screen absentees}

During the initial screening 13020 children were examined, out of whom 42 had RF/RHD. On subsequent visits to screen children who had been absent at the first visit, three cases of RF/ RHD were found in 2060 children, giving prevalence rates of 3.22 and 1.45 per thousand respectively.

AGE AND SEX DISTRIBUTION OF RF/RHD CASES

The mean (SD) age of the children with $\mathrm{RF}$ / RHD was $12.04(3 \cdot 1)$ years, ranging from 6 to 16 years. There were 30 cases $(3 \cdot 5 / 1000)$ of $R F /$ RHD in children aged 11-16 compared with 15 cases $(2 \cdot 29 / 1000)$ in the 5-10 years group as shown in table 1 . This difference was not statistically significant $(p>0.05)$. There were 23 boys $(2 \cdot 83 / 1000)$ and 22 girls $(3 \cdot 16 / 1000)$ with $\mathrm{RF} / \mathrm{RHD}$ but this difference was not significant $(p>0.05)$.

PREVALENCE OF RHD IN DIFFERENT CATEGORIES OF SCHOOLS

This is shown in table 2. The prevalence of definite RHD and the overall RHD prevalence was significantly higher in rural government schools $(4 \cdot 8 / 1000)$ and lowest in convent schools $(1 \cdot 6 / 1000)(p<0 \cdot 05)$.

PREVALENCE OF RHD IN RURAL AND URBAN AREA The prevalence of RHD was significantly higher in rural $(4 \cdot 8 / 1000)$ than in urban areas $(1.98 /$ 1000) $(\mathrm{p}<0 \cdot 05)$. The prevalence of definite RHD was also significantly higher in rural $(3 \cdot 81 / 1000)$ than in urban areas $(1 \cdot 29 / 1000)$ $(\mathrm{p}<0 \cdot 05)$

SOCIOECONOMIC STATUS

All the children screened were grouped into five social classes as given in table 3 . The prevalence of RF/RHD was high among lower social classes, but these differences were not significant $(\mathrm{p}>0.05)$

\section{HOUSING}

In most cases, that is $33(73 \cdot 3 \%)$, housing conditions were poor, there was no proper environmental sanitation and considerable overcrowding. Only $12(26.7 \%)$ lived in good conditions.

\section{PRESENTATION OF PATIENTS WITH RHD}

Most of the cases presented with a history of recurrent joint pains ( $84 \%$ ), and migratory joint pains were present in $21(47 \cdot 7 \%)$. A current history of joint pains was present in $10(22.72 \%)$ cases, out of whom eight $(18 \cdot 2 \%)$ had arthralgia and two $(4.5 \%)$ had arthritis. Of two cases of arthritis, all the major joints were involved in one and the other had knee joint involvement. Twelve $(27 \cdot 2 \%)$ cases presented with a history of an antecedent sore throat. A history of fever at the time of screening was present in five $(11 \cdot 36 \%)$ cases and $22(50 \%)$ cases presented with recurrent fever. Breathlessness and palpitation were present in $34(77 \cdot 3 \%)$ and 15 (34.1\%) cases respectively. Chest pain was present in seven $(15.9 \%)$ cases. The New York Heart Association (NYHA) functional classes of the patients were as follows: class $\mathrm{I}=13(38 \cdot 2 \%)$ $\mathrm{II}=13(38 \cdot 2 \%) ; \mathrm{III}=7(20 \cdot 6 \%) ; \mathrm{IV}=1(2 \cdot 9 \%)$

\section{CLINICAL AND ECHOCARDIOGRAPHIC PROFILE OF} PATIENTS WITH RHD

This is shown in table 4 . Of 44 cases of RHD, only $29(65.9 \%)$ gave a past history of RF, nine $(20 \cdot 5 \%)$ gave a previous history suggestive of $\mathrm{RF}$, and in six (13.63\%) there was no previous history of RF. Two cases who gave a past history of RF had only Gr II/VI functional murmur at the clinical examination but they were found to have mild mitral regurgitation on echocardiography. Similarly, one child with a previous history suggestive of RF and grade II/VI functional murmur was found to have definite RHD.

Of 44 cases, $10(22 \cdot 7 \%)$ were asymptomatic and $34(77.3 \%)$ were symptomatic. On clinical examination, there was murmur in $29(65.9 \%)$ cases. Three $(6 \cdot 8 \%)$ cases who were normal on 
Table 4 Clinical and echocardiographic profile of patients with rheumatic heart disease (RHD)

\begin{tabular}{|c|c|c|c|}
\hline Rheumatic fever status & Clinical CVS findings & Echocardiographic findings & $\begin{array}{l}\text { No of } \\
\text { patients }\end{array}$ \\
\hline \multirow{6}{*}{$\begin{array}{l}\text { Past history of RF } \\
(n=29)\end{array}$} & \multirow{3}{*}{$\begin{array}{l}\text { Definite RHD } \\
(\mathrm{n}=17) \\
\mathrm{Gr} I \mathrm{II} \text { I ESM at apex } \\
(\mathrm{n}=2) \\
\text { Normal } \\
(\mathrm{n}=3) \\
\text { (one case was with chorea) }\end{array}$} & Definite RHD & 17 \\
\hline & & Definite RHD (mild MR) & 2 \\
\hline & & Definite RHD (mild MR) & 3 \\
\hline & $\begin{array}{l}\text { (one case was with chorea) } \\
\text { Normal (with chorea) } \\
(n=1)\end{array}$ & Probable MV disease & 1 \\
\hline & Normal & Probable MV disease & 5 \\
\hline & $\begin{array}{l}\mathrm{Gr} \mathrm{I} / \mathrm{VI} \text { ESM at apex } \\
(\mathrm{n}=1)\end{array}$ & Probable MV disease & 1 \\
\hline \multirow{5}{*}{$\begin{array}{l}\text { Previous history suggestive } \\
\text { of } R F \\
(n=9)\end{array}$} & $\begin{array}{l}\text { Definite RHD } \\
(\mathrm{n}=3)\end{array}$ & Definite RHD & 3 \\
\hline & \multirow{3}{*}{$\begin{array}{l}\text { Gr II/VI ESM at apex } \\
(n=1) \\
\text { Normal } \\
(n=4)\end{array}$} & Definite RHD (mild MR) & 1 \\
\hline & & Probable MV disease & 3 \\
\hline & & $\begin{array}{l}\text { Probable } \mathrm{MV} \text { and } \mathrm{AV} \\
\text { disease }\end{array}$ & 1 \\
\hline & $\begin{array}{l}\text { Gr II/VI ESM at apex } \\
(n=1)\end{array}$ & Probable MV disease & 1 \\
\hline \multirow{2}{*}{$\begin{array}{l}\text { No past history of RF } \\
(n=6) \\
\text { Total }\end{array}$} & $\begin{array}{l}\text { Definite RHD } \\
(\mathrm{n}=6)\end{array}$ & Definite RHD & 6 \\
\hline & & & 44 \\
\hline
\end{tabular}

$\mathrm{MV}=$ mitral valve; $\mathrm{AV}=$ Aortic valve; $\mathrm{MR}=$ Mitral regurgitation; $\mathrm{CVS}=$ cardiovascular system; $\mathrm{ESM}=$ ejection systolic murmur

Table 5 Type of valvular lesion

\begin{tabular}{|c|c|c|c|c|c|}
\hline \multirow[t]{2}{*}{ Type of lesion } & \multicolumn{3}{|c|}{ No of children } & \multicolumn{2}{|c|}{$\%$ of total } \\
\hline & Male & Female & Total & Male & Female \\
\hline $\begin{array}{l}\text { MR } \\
\text { MS } \\
\mathrm{AR} \\
\mathrm{MR}+\mathrm{MS} \\
\mathrm{MR}+\mathrm{AR} \\
\mathrm{MR}+\mathrm{TR} \\
\mathrm{MS}+\mathrm{TR} \\
\mathrm{MS}+\mathrm{AR}+\mathrm{TR}+\mathrm{TS} \\
\mathrm{MR}+\mathrm{MS}+\mathrm{TR}+\mathrm{TS}+\mathrm{AR}+\mathrm{AS} \\
\text { Total }\end{array}$ & $\begin{array}{l}6(40 \cdot 0) \\
1(6 \cdot 7) \\
1(6 \cdot 7) \\
1(6 \cdot 7) \\
2(13 \cdot 3) \\
2(13 \cdot 3) \\
1(6 \cdot 7) \\
0 \\
1(6 \cdot 7) \\
15(100) \\
\chi^{2}=4 \cdot 89\end{array}$ & $\begin{array}{l}10(58 \cdot 2) \\
0 \\
0 \\
1(5 \cdot 8) \\
2(11 \cdot 8) \\
2(11 \cdot 8) \\
1(5 \cdot 8) \\
1(5 \cdot 8) \\
0 \\
17(100) \\
p>0 \cdot 05)\end{array}$ & $\begin{array}{l}16(50 \cdot 0) \\
1(3 \cdot 1) \\
1(3 \cdot 1) \\
2(6 \cdot 3) \\
4(12 \cdot 5) \\
4(12 \cdot 5) \\
2(6 \cdot 3) \\
1(3 \cdot 1) \\
1(3 \cdot 1) \\
32(100)\end{array}$ & $\begin{array}{l}37 \cdot 5 \\
100 \\
100 \\
50 \\
50 \\
50 \\
50 \\
0 \\
100\end{array}$ & $\begin{array}{l}62 \cdot 5 \\
0 \\
0 \\
50 \\
50 \\
50 \\
50 \\
100 \\
0\end{array}$ \\
\hline
\end{tabular}

Figures given in parentheses indicate percentage

$\mathrm{MR}=$ mitral regurgitation; $\mathrm{AR}=$ aortic regurgitation; $\mathrm{TR}=$ tricuspid regurgitation; $\mathrm{MS}=$ mitral stenosis; AS = aortic stenosis; TS = tricuspid stenosis.

clinical examination were found to have definite RHD on echocardiographic examination. A previous history of chorea was present in five $(11 \cdot 4 \%)$ cases. No case gave past history of subcutaneous nodules or erythema marginatum. Pharyngitis was present in $24(54 \cdot 5 \%)$ cases at the time of examination. Two $(4 \cdot 54 \%)$ cases had congestive cardiac failure. Pulmonary arterial hypertension was present in nine $(20.5 \%)$ cases and pulmonary venous hypertension in five $(11 \cdot 36 \%)$ cases. Endocarditis was present in one $(2 \cdot 3 \%)$ case and pedal oedema in two $(2 \cdot 3 \%)$.

VALVULAR INVOLVEMENT AND TYPE OF VALVULAR LESION

Of the 44 cases, the mitral valve was involved in $43(97.7 \%)$, the aortic valve in nine $(20.5 \%)$, and the tricuspid valve in eight $(20 \cdot 5 \%)$. No case of pulmonary valve involvement was found. The type of valvular lesion is given in table 5 . Of the 44 cases of RHD, $32(72 \cdot 7 \%)$ had definite RHD and the remaining $12(27 \cdot 3 \%)$ had echocardiographic evidence of valvular involvement with no definite valvular dysfunction. Mitral regurgitation was the commonest lesion (50\%) in these 32 cases.
SEVERITY OF VALVULAR DISEASE IN RHD CASES

One of 15 cases $(6 \cdot 7 \%)$ in the $5-10$ years group had a severe valvular lesion compared with five of $29(17 \cdot 2 \%)$ in $11-16$ years age group.

LABORATORY INVESTIGATION IN RHD CASES

The ASO titre was raised in six (13.6\%) cases; the $\mathrm{C}$ reactive protein test was positive in only one $(2.3 \%)$ case; the erythrocyte sedimentation rate was raised in $11(25 \%)$ cases; and throat swab culture for $\beta$ haemolytic streptococci (BHS) was positive in $20(45.5 \%)$ cases. Five cases $(11.4 \%)$ had both a raised ASO titre and throat swab positive for BHS. Clinical examination showed that pharyngitis was present in $24(54 \cdot 5 \%)$ cases, $14(58 \cdot 2 \%)$ of whom were positive for BHS.

\section{SECONDARY PROPHYLAXIS}

Only 27 of the $44(61 \cdot 4 \%)$ cases were taking secondary prophylaxis with penicillin at the time of the study. Of these, $10(37 \%)$ who were on secondary prophylaxis were positive for BHS on throat culture and only two were taking it irregularly. Of four cases with RF recurrence, only two $(50 \%)$ were on secondary prophylaxis, though they were taking it irregularly.

\section{PROFILE OF THE FIRST ATTACK OF RF}

Out of the three cases of acute RF, two $(66 \cdot 7 \%)$ had carditis and one $(33.3 \%)$ had no carditis. Arthritis was seen in two $(66 \cdot 7 \%)$ cases. Subcutaneous nodules were present in one case only. No case was seen with chorea and erythema marginatum. Two cases of acute RF were positive for BHS on throat culture.

\section{Discussion}

This study tried to determine the prevalence of RHD/RF in school children aged 5-16 years in the state of Himachal Pradesh. This work is the first of its kind in the last 30 years and covers a large number $(n=15080)$ of school children. It is one of the largest studies undertaken in India.

In this study, all 26 cases found to be clinically definite were confirmed by echocardiography. However, only $24 \%$ of clinically probable cases were found to have RHD by echocardiography, thereby indicating the low specificity of clinical observation. Hence, identification of RHD by clinical criteria is bound to overdiagnose the disease in community surveys. Similarly, six children whose diagnosis was uncertain after clinical examination were found to be suffering from definite RHD echocardiographically, indicating a low sensitivity of the clinical diagnosis. Echocardiography also enabled us to make a probable diagnosis of RHD in $12(16 \%)$ of 75 clinically suspected RHD cases in whom there was echocardiographic evidence suggestive of RHD. The roles of echocardiography and Doppler ultrasonography as highly sensitive and specific tools in the assessment of RHD have been emphasised in various studies from all over the world. ${ }^{56}$

In our target population (5-16 years) of 15080 , the prevalence of RF/RHD was 2.98 per 
thousand, comparable with a recently published report of the prevalence of RHD ( $2 \cdot 2$ per thousand) in 16 developing countries of five WHO regions. ${ }^{7}$ The prevalence of $\mathrm{RF} / \mathrm{RHD}$ in the present study was less than the 11 per thousand reported from Sahafa town, Sudan, ${ }^{8} \mathrm{com}-$ parable with 2.4 per thousand reported from Saudi Arabia ${ }^{9}$ but higher than the 1.7 per thousand reported from western $\operatorname{Kenya}^{10}$ and is also slightly higher than that reported from our neighbouring countries. ${ }^{112}$

If the prevalence rates of RHD in different parts of India are compared our rate was less than those of Calcutta and Hyderabad ${ }^{2}$ and slightly higher than those of Alleppy, Bombay ${ }^{2}$ and Anand. In northern India, the prevalence of RHD in our study was comparable with those in neighbouring states ${ }^{13-16}$ but lower than that in Delhi. ${ }^{17}$ It was observed that there was not much difference in the prevalence of RHD where echocardiography had been used. ${ }^{14-16}$ The prevalence of RHD in our study was higher in rural areas $(4 \cdot 8 / 1000)$ a finding also reported from Saudi Arabia ${ }^{9}$ and from school children in a country town in Ethiopia. ${ }^{18}$ Koshi et al reported a RHD prevalence of 4.9 per thousand in rural south Indian children. ${ }^{19}$ In a recent survey from rural area of Rajasthan, the prevalence of RHD was 3.34 per thousand where echocardiography had been used. ${ }^{15}$ So the problem of RHD is still higher in rural areas of India.

The RHD prevalence was highest in government schools in our study as in other studies. ${ }^{1720}$ It was slightly higher in the 11-16 years age group than in the 5-10 years groups, in agreement with other studies. ${ }^{1417}$ The RHD prevalence was almost equal in both sexes, as has been reported by others. ${ }^{10111617}$ The prevalence of RF/RHD on subsequent visits to screen those children who were absent at the first visit was lower $(1 \cdot 45 / 1000)$ than in the initial screening (3-22/10,00). This may be due to some other causes than RF/RHD but every effort should be made to achieve as high a coverage as possible to get true picture of the disease.

There was a clear trend of an increasing prevalence of RHD with a fall in the socioeconomic status, though the difference was not significant as in other studies. ${ }^{13-16}$ It has been reported that the prevalence of RF/RHD increases directly with overcrowding and poor housing. ${ }^{8}$ Overcrowding and poor housing were present in most of our subjects though no valid inference could be drawn due to lack of controls for comparison.

About $66 \%$ of our cases gave a past history of RF, compared with $6.2 \%$ in the study of Berry ${ }^{12}$ and $40 \%$ in a study of Shimla by Chand. ${ }^{11}$ Eighty four per cent of the children with RHD gave past history of recurrent joint pains, $48 \%$ of migratory joint pains, and $11.36 \%$ of chorea hence chorea was not as uncommon as has been believed by others.

In a school survey in Delhi, $18 \%$ of cases of RHD gave past history of polyarthritis, $26 \%$ of migrating polyarthralgia, and $3 \%$ of chorea. ${ }^{17}$ Berry found polyarthritis, polyarthralgia, and fever as the commonest combination and a history of chorea was present in only six cases. ${ }^{21}$ Subcutaneous nodules are also not as uncommon as previously thought. Erythema mar- ginatum has been reported from India by many workers but was not seen here. ${ }^{21}$

Isolated mitral regurgitation was commonest lesion, as had been reported in India by many workers. ${ }^{131720}$ It was followed by combined mitral and atrial regurgitation and combined mitral and tricuspid regurgitation, each found in $12.5 \%$ of cases. Isolated mitral stenosis and isolated atrial regurgitation were present in $3 \cdot 1 \%$ cases each. Isolated mitral stenosis in the present study was less frequent than reported by others. ${ }^{1720}$

RHD with severe valvular lesion was more common in the 11-16 years age group than in the children aged $5-10$ years. There is therefore a need to identify cases early when the valvular lesion is less severe and to give them secondary prophylaxis with penicillin thereby preventing recurrence and progression of the severity of the valvular lesion.

About a quarter of the cases of RHD were asymptomatic: these children did not attend the hospital and were not taking secondary prophylaxis with penicillin. Survey studies are therefore needed to identify these asymptomatic patients.

The carrier rate of BHS had been reported as $34 \%$ in Saudi Arabia ${ }^{9}$ and $24 \%$ in RHD cases in Delhi. ${ }^{17}$ Our carrier rate was $45 \%$, which can be attributed to the poor living conditions prevailing in the area. Despite secondary prophylaxis in 27 cases, 10 (37\%) children were positive for BHS on throat culture and only two of them were taking penicillin irregularly.

Some $38.6 \%$ of RHD cases were not taking secondary prophylaxis with penicillin. The role of secondary prophylaxis in RHD patients has been emphasised by many studies. ${ }^{5}$ These patients need to be educated about the importance of secondary prophylaxis.

1 Padmavati S. Community control of rheumatic heart disease in developing countries. World Health Organization Chronin developing countries.

2 Indian Council of Medical Research. Progress in cardiovascular disease research in India during the last two decades (1971-92). Indian Council of Medical Research Bulletin 1992;22(4):46-7.

3 Shrestha UK, Bhattarai TN, Pandey MR. Prevalence of rheumatic fever and rheumatic heart disease in school children in a rural community of the hilr region of Nepal. Indian Heart $\Im 1991 ; 43(1): 39-41$

4 Kumar P. Social classification - need for constant updating. Indian fournal of Community Medicine 1993;XVIII(2): 60-1.

5 World Heath Organisation. Rheumatic heart disease: report of a WHO study group. Geneva: WHO, WHO Tech Rep Ser No $764,1988$.

6 Veasy LG, Weidmeier SE, Ormond GS et al. Resurgence of acute rheumatic fever in the intermountain area of the United States. $N$ Engl $f$ Med 1990;316(8):42:1-7.

7 WHO cardiovascular disease unit and principal investigators. WHO programme for the prevention of rheumatic fever/rheumatic heart disease in 16 developing countries: report from phase I (1986-90). Bull WHO $1992 ; 70(2): 213-8$

8 Ibrahim-Khalit S, Ethag M, Ali E et al. An epidemiologica survey of rheumatic fever and rheumatic heart disease in Sahafa town, Sudan. $f$ Epidemiology Community Health 1992;46:477-9.

9 Al-Sekait MA, Al-Sweliem AA, Tahir M. Rheumatic heart disease in school children in the Western district, Saud Arabia. F R Soc Health 1990;11(1):15-6,19.

10 Arabwani GM, Amoa AB, Muita AK. Epidemiology of rheumatic heart disease among primary school children in Western Kenya. Int $\mathcal{F}$ Cardiol 1989;23(2):249-52.

11 Chand D. Rheumatic fever and rheumatic heart disease in Shimla hills: Epidemiological aspect. Indian $\mathcal{f} M e d ~ R e s$ 1963;5.1(3):407-18

12 Jamal M, Abbas KA. Clinical profile of acute rheumatic fever in children. 7 Trop Pediatr 1989;35:10-3.

13 Avasthi G, Singh D, Singh C, Aggarwal SP, Bidwai PS, 
Avasthi R. Prevalence survey of rheumatic fever and rheumatic heart disease in urban and rural school children. Indian Heart $f 1987 ; 39(1): 26-8$.

14 Gupta I, Gupta ML, Parihar A, Gupta CB. Epidemiology of rheumatic and congenital heart disease in school children. F Indian Med Assoc 1992;90(3):57-9.

15 Kumar P, Garhwal S, Chaudhary V. Rheumatic heart disease: a school survey in a rural area of Rajasthan. Indian Heart $\mathcal{F} 1992 ; 44(4): 245-6$.

16 Grover A, Dhawan A, Iyengar SD, Anand IS, Wahl PL Ganguly NK. Epidemiology of rheumatic fever and rheumatic heart disease in a rural community in northern India. Bull WHO 1993;71(1):59-66.

17 Shrestha NK, Padmavati S. Prevalence of rheumatic heart disease in Delhi school children. Indian 7 Med Res 1979; 69:821-33.

18 Oli K, Tekle Haimanot R, Forsgren L, Ekstedt J. Rheumatic heart disease prevalence among school children of an Ethiopian rural town. Cardiology 1992;80(2):152-5.

19 Koshi G, Benjamin V, Cherian G. Rheumatic fever and rheumatic heart disease in rural south Indian children. Bull WHO 1981;59(4):599-03.

20 Mathur KS, Wahal PK. Epidemiology of rheumatic hear disease - a study of 29922 school children. Indian Hear f 1982;34(6):367-71.

21 Berry JN. Prevalence survey of chronic rheumatic heart disease and rheumatic fever in Northern India. $\mathrm{Br}$ Hear f 1972;34:143-9. 